\title{
ON THE RADULA OF THE BRITISH HELICIDS. (PART III.)
}

\author{
By Rev. E. W. Bowell, M.A.
}

Read 11 th June, 1909.

Тнв radulæ to be described in the present paper are those of virgata, cantiana, revelata, sericea, hispida, rufescens, caperata, Itala, barbara, and granulata. Generic names will not be mentioned for the present; and to avoid confusion the species will be mentioned in the above order, which is the result of a classification of the peculiarities of the radulæ.

On p. 126 of Volume VIII of these "Proceedings" I stated that barbara differed from the other small Helices of this group in the possession of bifid marginal mesocones. Closer examination of better mounted specimens has shown that this character also is found in caperata, Itala, and granulata; this will be noted in the accompanying illustrations. This correction is of great importance, since it appears probable that the species possessing this character are nearer to the larger Helices than to those in which it is not present. By the term 'larger Helices' I mean the species described in Part II of these notes, purposely using an unscientific phrase, because the limits of this group are very vague to me at present. The study of this particular point has emphasised an opinion towards which I have inclined for a long time, namely, that size has counted for too much in our systems of classification. I was led to look out for large species which might be supposed to be magnified races derived from known smaller species; and also for small species which appear to be the starved representatives of larger ancestors. Instances of this kind of thing are not rare amongst insects, but probably there is no part of the animal kingdom where they are more frequent than in that to which our studies are devoted. On examining these pairs of forms we do not find that they are ever the exact counterparts of each other; and the same is true of large and small races occurring in the same species. Increase of size or diminution of size involve in every case a redistribution of symmetry, because the constituent cells of the organism do not share the increase or diminution. In the case of some organs it matters more, and in the case of other organs it matters less, that the general scale of the organism should be increased or diminished. The radula appears to be an organ that does not readily vary in size with the general scale of the organism. It has already been pointed out that in our British Helicidæ the size of the radula is not proportionate to the size of the animal, though the proportion it bears is closer than in some other groups. This is true also of the individual unci. But the individual unci of Zonites Algirus are not larger than those of Vitrea lucida, consequently there must be, and there are, many more of them. And since the number of unci is multiplied, their form is altered; they are simplified so that the admedians resemble Helicid admedians in general appearance. If we 


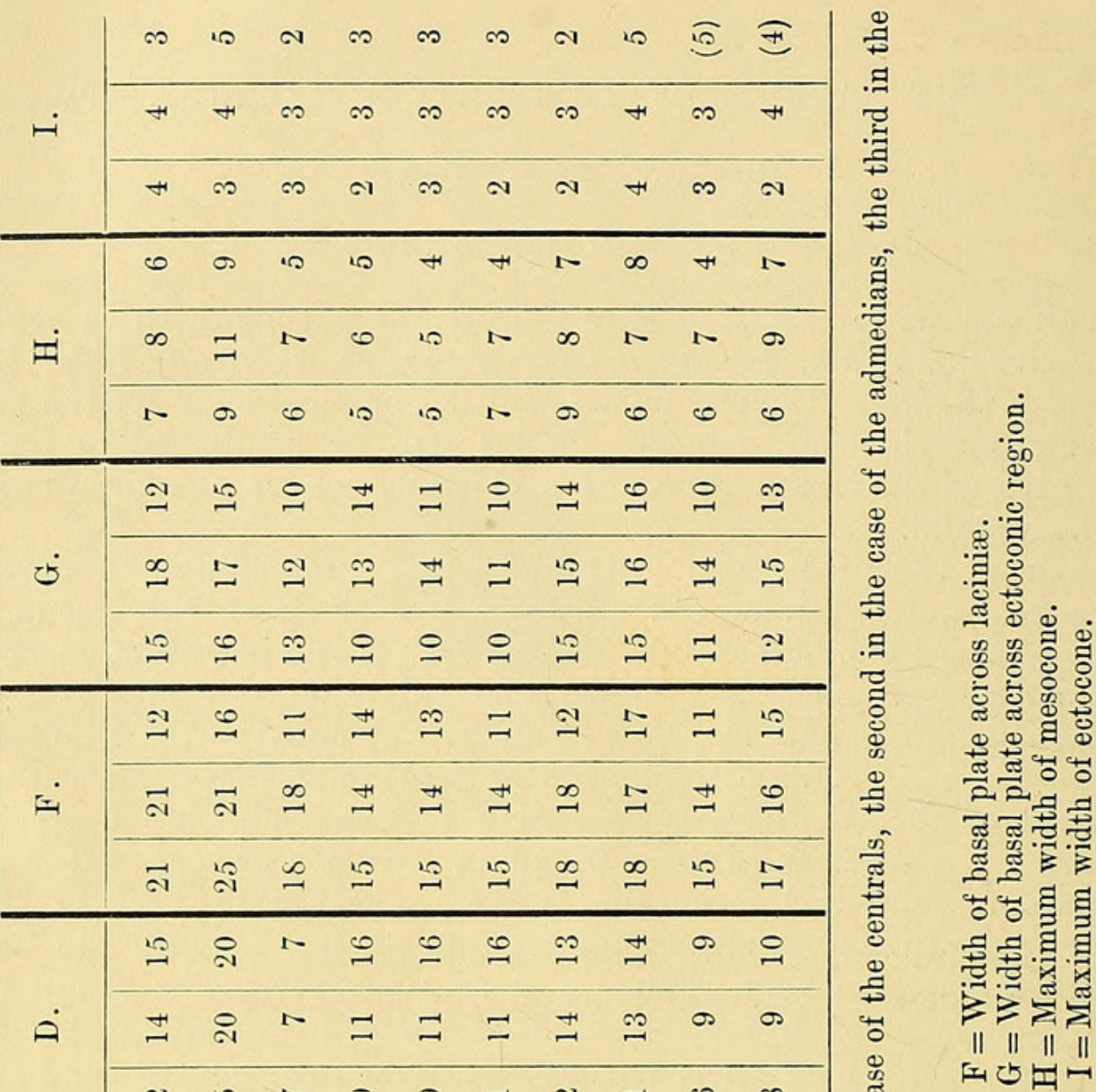

न्ट

क्ष

竞

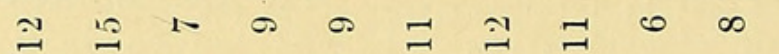

ฮ

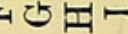

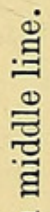

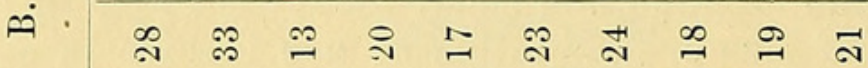

ก 2 \#

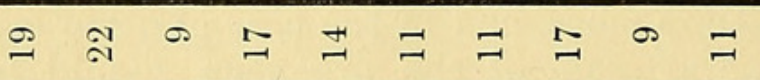

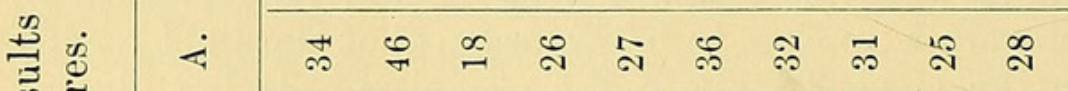

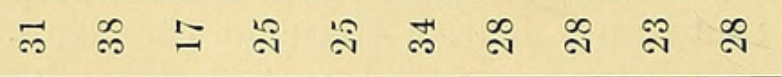

.$\Xi$ 
examine the rest of the anatomy of $Z$. Algirus, we find that it is quite of the true Vitrea type, except for such modifications as are evidently the result of its hypertrophic growth. All our Helicidæ, with the exception of the Vallonias, present the character of many admedians, but especially is this the case with the larger specimens and larger individuals; and this holds good with regard to the Succinea also. The fact assumes a special importance when we observe that it is an example of change in size inducing definite type of morphological change, and doing so for a mechanical reason which it is not hard to understand. As the causes of change in size may be traced back to the action of cosmic forces, acting rhythmically during the whole of the biological period, this definite change of symmetry which results from change of size may be supposed to form an important factor in evolution.

Let us next ask ourselves what is the significance of the marginals. It is possible to tell at a glance in most cases whether we are dealing with a Limacid, or a Succinea, or a Helicid, by looking at the marginals; and, as has already been mentioned, there are two Helicid types, one with bifid mesocone (like the Helices), and the other with simple mesocone (like the Arions). What is the relationship between these two forms? The latter is illustrated in the first six of the species described in this paper.

Measurements, additional characters, and diagnostic notes are here given according to the plan adopted in Part II.

\section{ADDITIONAL CHARACTERS.}

[The first description in each case is that of the centrals, the second of the admedians, and the third of the externals.]

(a) Shape of basal plate.

virgata. Rounded oblong, larger below; not markedly alate; upright oblong, upper margin irregular.

cantiana. With indentations above and below; alate; subtetragonal. revelata. Roughly hexagonal; modified central; depressed oblong. sericea. Upright oblong; as central; squared.

hispida. As sericea, but more curved. (See note below.)

rufescens. As hispida, but generally more elongated.

caperata. As virgata, but externals small, irregular.

Itala. Roughly hexagonal; rounded oblong; irregular triangulate.

barbara. Key-shaped, doubly notched below; first oblongate, then alate; depressed oblong.

granulata. Rounded oblong, larger below; rhomboid; depressed oblong.

(b) Character of lower corners of basal plate.

virgata. Rounded; inclined; squared.

cantiana. As virgata, but with characters intensified.

revelata. All considerably shortened.

sericea. Angles not prominent.

hispida. Approaching virgata type. 
rufescens. As cantiana, except central (see plate); externals truncate.

caperata. As virgata; externals minute.

Itala. As virgata, but externals sometimes acute.

barbara. Various, as plate; not irregular.

granulata. Rounded; rounded; rectangular.

(c) Shape of lower edge of basal plate.

virgata. Slight incurvations.

cantiana. Notched; irregularly notched; straightened.

revelata. All slightly incurved.

sericea. All slightly incurved; transitionals more incurved.

hispida. Very slight incurvation.

rufescens. Straight; incurved; straight.

caperata. Double curve ; curved ; irregular.

Itala. Incurved; various; irregular.

barbara. Double outward curve ; various; slightly incurved.

granulata. Incurved; straightened; straightened.

(d) Shape of apex.

See plate. The pointed form, as in Itala, is found in transitionals of several species, especially sericea and hispida. Incurvation or acumination in central is partly a matter of thickness or thinness of growth.

$(f)$ Number and character of cones visible.

virgata. $3 ; 2 ; 2$.

cantiana. $3 ; 2 ; 2$; accessories evanescent.

revelata. $3 ; 2 ; 2$.

sericea and hispida. $3 ; 2 ; 2$.

rufescens. 3 (ectocones minute); $2 ; 2$ or 3 .

caperata. $3 ; 2 ; 4$ ( 3 if bifid mesocone be secondary).

Itala. As caperata, but second accessory external often missing.

barbara. $3 ; 2 ; 3$ to 5 .

granulata. $3 ; 2 ; 4$ or 5 .

\section{Diagnostic Notes.}

In cantiana the admedians approach those of hortensis and nemoralis in respect of rotundity. The shape of the basal plates distinguishes cantiana from virgata. Revelata shows remarkably shortened and squared unci and plates; in sericea and hispida both are lengthened. The pointed apex shown in sericea is characteristic, but not so marked in immature specimens; it is due to a general strengthening and thickening of the backbone of the mesocone, if we may so speak. The 'knife-blades' (external mesocones) of these two species differ in slenderness, and further variations are found in other forms belonging to the same group. Those of rufescens are uniformly narrower. The base of the cusps in this species is larger, and it will be observed that where enlargement occurs it seems first to appear in this region; compare the figures of pomatia and its allies. The bifid mesocones of externals mark the remaining four species here described; in Itala this 
character invades the admedians also to some extent, and this is occasionally to be seen in caperata also. Barbara is distinguished from Itala by many differences, but the shape of the external apices seems one of the most interesting. Gramulata seems nearer to fusca than other members of this group.

The accompanying figures (pp. 384-7) are all drawn to the same scale; the scale will be found next to the figure of gramulata. It has been thought desirable to add figures of the larger Helicids also, and all of these have been redrawn under the same conditions and to the same scale. The magnification of the original drawings is 1,200 diameters. 


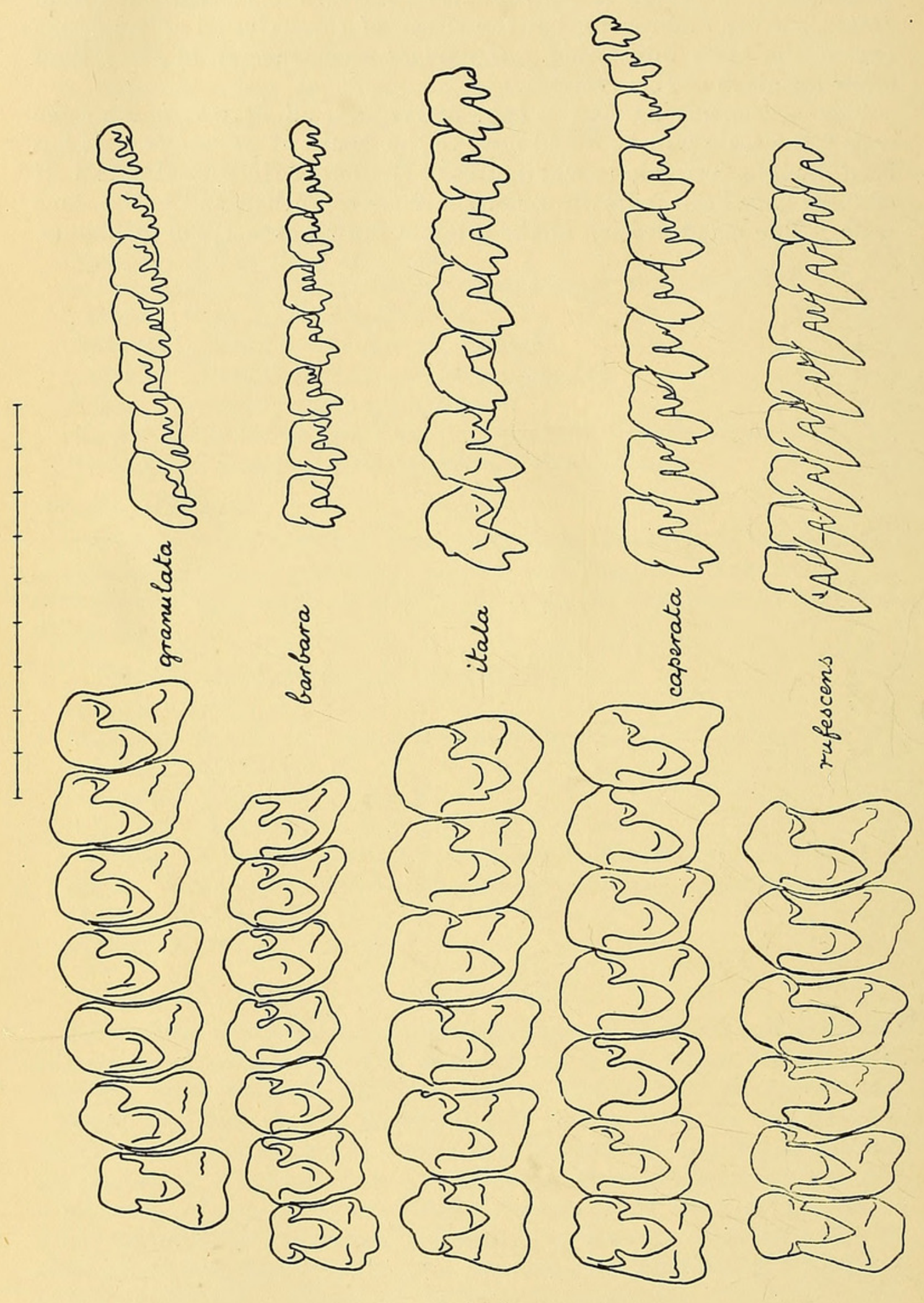

Radule of British Helicids. 


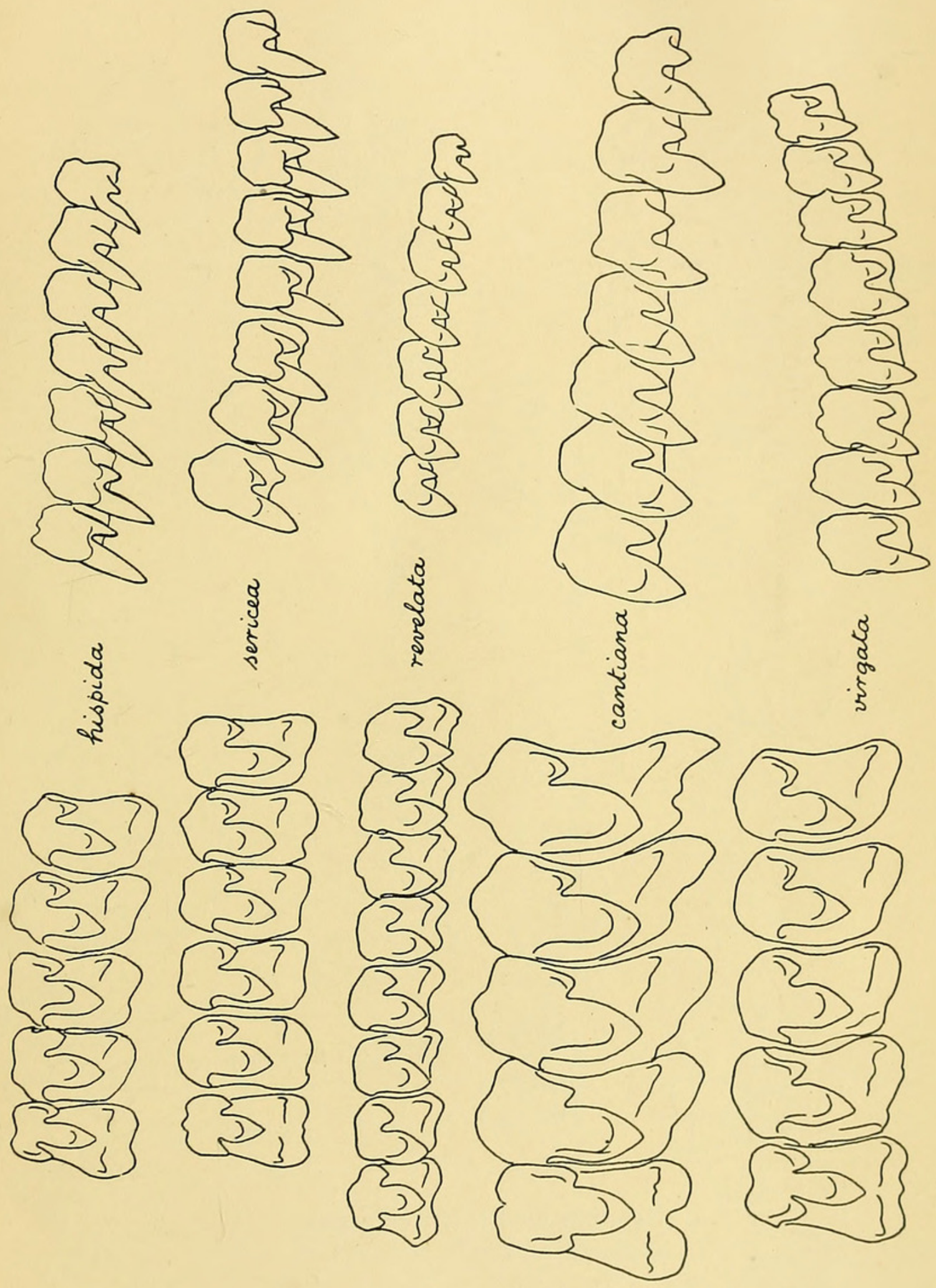

Radule of British Helicids. 

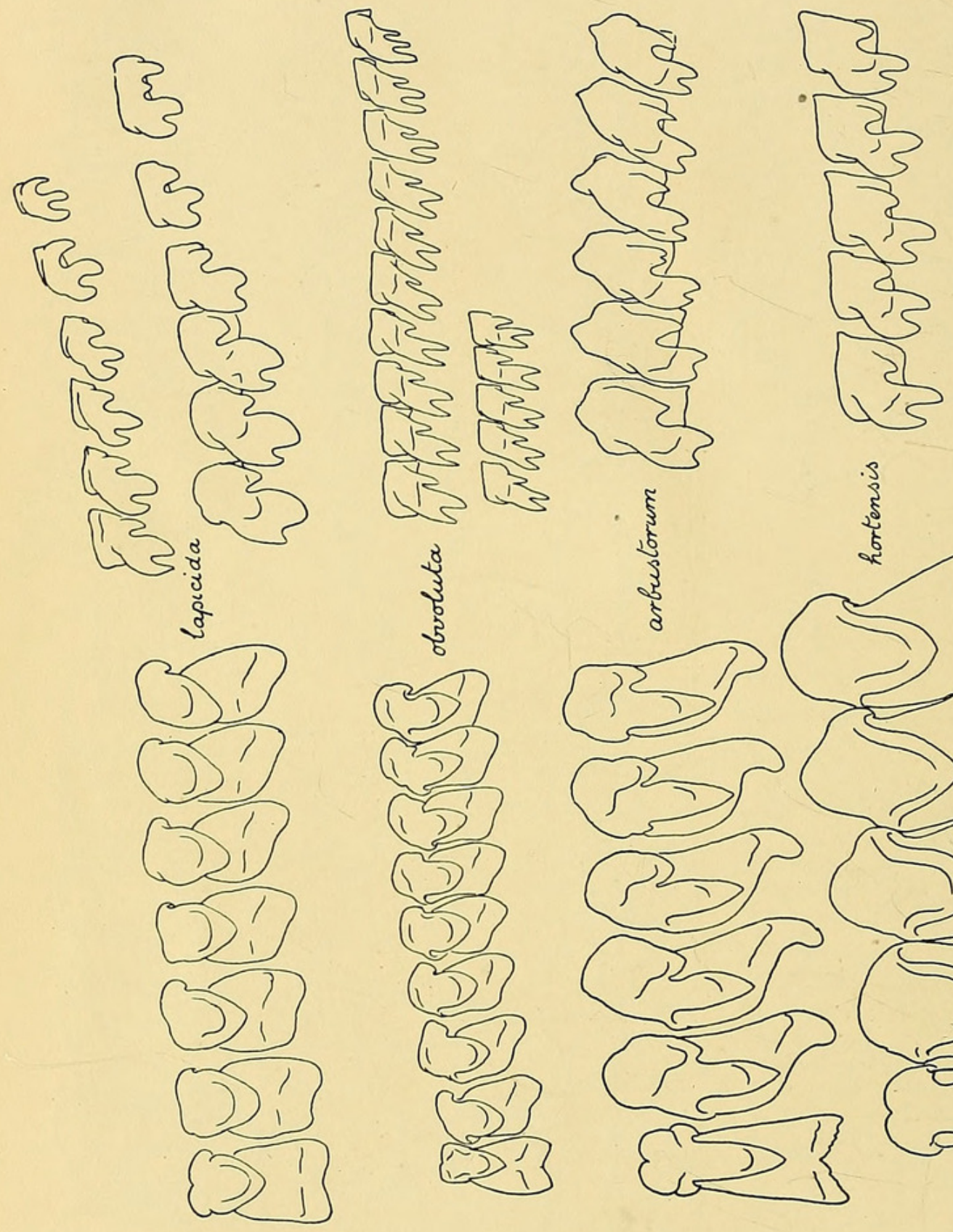

ईई
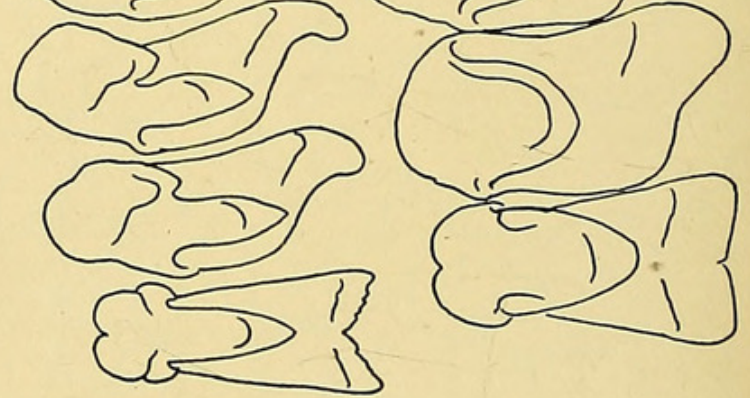

Radul a of British Helicids. 


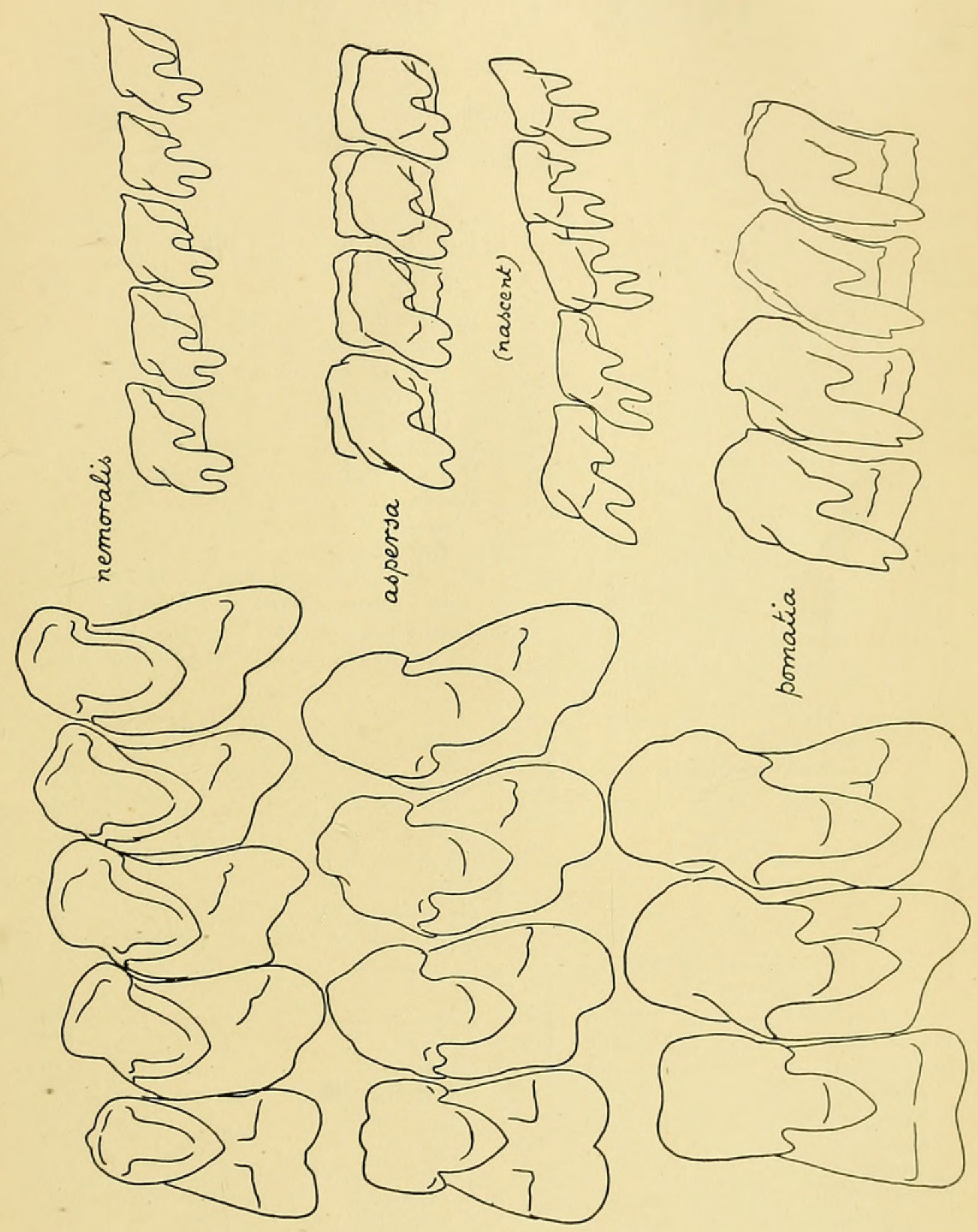

Radule of British Helicids. 


\section{$2 \mathrm{BHL}$ Biodiversity Heritage Library}

Bowell, E. W. 1909. "ON THE RADULAE OF THE BRITISH HELICIDS. (PART III.)." Proceedings of the Malacological Society of London 8, 379-387.

View This Item Online: https://www.biodiversitylibrary.org/item/100060

Permalink: https://www.biodiversitylibrary.org/partpdf/203018

\section{Holding Institution}

Field Museum of Natural History Library

\section{Sponsored by}

Smithsonian

\section{Copyright \& Reuse}

Copyright Status: Public domain. The BHL considers that this work is no longer under copyright protection.

This document was created from content at the Biodiversity Heritage Library, the world's largest open access digital library for biodiversity literature and archives. Visit BHL at https://www.biodiversitylibrary.org. 